\title{
Design of Prefabricated External Thermal Insulation System with Point Supported Horizontal Keel
}

\author{
Shibing Sun ${ }^{1,}$, Lu Zhang ${ }^{1, ~ b}$, Wanjin Wang ${ }^{2, ~ c}$, Donghua Liü, d \\ ${ }^{1}$ College of Materials Science and Engineering, Beijing University of Technology, China; \\ ${ }^{2}$ Beijing Building Construction Research Institute Co., Ltd., China; \\ ${ }^{3}$ First New Materials and Technology Developing Co., Ltd., China \\ a sunshibing@bjut.edu.cn, b1327977894@qq.com, \\ c wangwanjincls@163.com, d13681495665@163.com
}

\begin{abstract}
Keywords: External thermal insulation system ( ETIS ); Prefabricated; Point supporting; Horizontal keel

Abstract. Based on the basic thought of industrialized building, one prefabricated external thermal insulation system( ETIS )with point supported horizontal keel was designed in this paper. Bad support was fastened on the structural wall and horizontal keel was fastened on bed support. Then panel was fixed on horizontal keel by interdigitated cards and moreover thermal insulation material was fastened on the structural wall independently. ETIS has the ability to adjust the three-dimension and angle. The installation of panel could not only be invisible, but also be disassembled independently. The test result indicated that weathering resistance could meet the requirements of relevant standards and the maxima of wind resistance could be up to $-6300 \mathrm{~Pa}$. In addition, panel deformation performance, air impermeability and water tightness could reach grade 5 , grade 4 and grade 5 , respectively.
\end{abstract}

\section{Introduction}

Insulation materials are attached to external wall securely by using a particular structure form to constitute ETIS. In the traditional ETIS, insulation materials were attached to external wall by polymer cement mortar, and then polymer cement mortar, in which glass fibre grid cloth was embedded, was attached to the surface of insulation material to get the covering layer. At last, the dope was put on the covering layer. This construction method belongs to wet construction, which needs multiple plastered works and has a lot of processes and pollution during construction. Besides, it is difficult to control the quality as it is determined by operators.

With the development of industrialized building thought, the new thermal insulation system has been developed. The fastest two are decoration-insulation system and prefabricated insulation system which is based on the concept of curtain wall. For the decoration-insulation system, the panel (thin stone, metal plate, decorative cement board, et al) and thermal insulation materials are pasted in advance together to form the decoration-insulation panel which is attached to external wall with mechanical method. While the main idea of prefabricated ETIS is that materials are pre-cast in factory, and they are installed and assembled in construction site, reducing the secondary operation.

There are some researches and designs on fabricated and precast ETIS at home ${ }^{[1-2]}$ and abroad ${ }^{[3-6]}$. Zhuoda New Materials and Technology Group Co., Ltd. invented a gas gel of the heated board of building ETIS. Gel insulating board was fastened by keels and anchors ${ }^{[7]}$. Yajun Wang designed a two-way keel, and insulation board including u-shaped groove was stuck to keel ${ }^{[8]}$. In addition, China State Construction Engineering Corporation projected an assembly type external wall heat-preserving and decoration structure system, where the support was made up of I-shaped keel and Z-shaped connecting piece with connecting pore and the decoration-and-insulation board was stuck to the groove on both sides of I-shaped keel before ETIS was fixed on structural wall ${ }^{[9]}$. Biebricher B invented and opened the composite system for thermal insulation of external walls to prevent heat loss and the system had multiple heat insulating panels forming composite surface and were mounted on 
outer wall of building by bonding and anchoring ${ }^{[10]}$. Sugawara M and Miyamoto N. designed a back ventilated paste-installation method for thermal insulation material ${ }^{[11]}$. Young $\mathrm{S} J$ designed a external thermal insulation system whose external was thermal insulation material with internal installing holes. Its frame structure was fixed with a lot of fixtures and its thermal insulation material was inserted into the frame structure whose end inserted into the mounting holes on the wall ${ }^{[12]}$. Yeol S D designed a high insulation double layer panel system for construction of outer wall side of building, which had fixed bar that was combined in frame of building and structure so that honeycomb panel was adhered in one end of spacer for heat insulation ${ }^{[13]}$. Yeon Y J et al. designed an external thermal insulation system which could prevent thermal bridge effect efficiently ${ }^{[14]}$.

This paper designed a prefabricated ETIS with point supported horizontal keel guided by the ETAG 004 principles $^{[15]}$ (European Technical Approval of External Thermal Insulation Composite Systems with Rendering).

\section{The System Design Principle}

There is no mature theory or technology about design of prefabricated ETIS. Based on the relevant design ideas of decoration-and-insulation board and curtain and the ETAG 004 principles, the principles and guiding ideology of this study are as follows:

(1) Dry assembly construction principle

The prefabricated ETIS is based on the idea of industrialized building

(2) Precast principle

There are two obvious advantages of prefabrication. The first one is that the quality is easy to control, such as routing quality's monitoring and control. The second one is that it could reduce the waste at the construction field, which is because the waste in factory could be recycled.

(3) Principle of system security

It is essential to calculate and verify the security of structural mechanics as the wind load shouldn't be ignored in ETIS. To ensure the security in unforeseen circumstances, this system needs to adopt the mechanical anchor fixation.

(4) Principle of heat preservation functionality

In view of the requirements of building energy efficiency from different areas, fabricated insulation system could suit different heat insulating materials and the thickness of insulation layer. Meanwhile, it needs to reduce the design of "broken bridge" in hot and cold bridge because the fixed way is the keel.

(5) Principle of installed convenience

The strong points of fabricated insulation system is its convenience in construction and installation, especially in energy-saving renovation of existing buildings whose special construction environment needs the system to meet a series of requirements, such as convenient installation, short construction period, less environmental pollution and little disturbance.

(6) Principle of economic rationality

To ensure the performance of the fabricated ETIS, we should also take cost into a reasonable range by selecting reasonable materials. The economic rationality of the ETIS includes the economy of material and the convenient installation. The former one is to reduce the cost of material and the latter one is to reduce the installation cost in construction.

\section{The Basic Structure of the System}

According to the above principles, the basic structure of fabricated ETIS is shown in Fig. 1. The bed support is fixed on structural wall by metal anchor bolt at predetermined intervals and thermal insulation material is fixed by insulation anchor. Horizontal keel is installed on support arms with bolt wherein heat insulation pad whose height can be adjusted is inserted and angle adjustment pad would be inserted when needed. The panel clamp unit is fixed on horizontal keel, and inserted into the groove on the side of the panel. Then panels are sealed by sealant. 


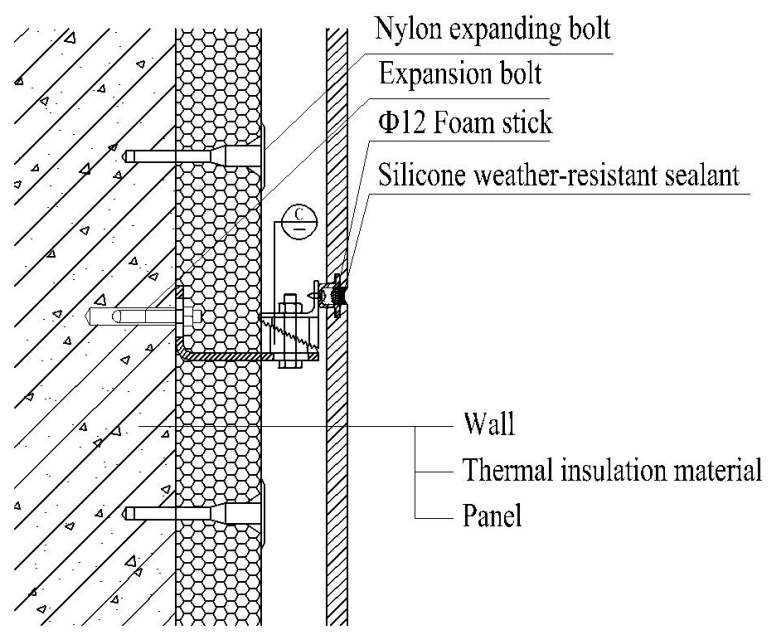

Fig.1. Basic structure of ETIS

\section{Material Design of the System}

\section{(1) Bed support}

The connector of fabricated ETIS is fixed on grass-roots wall by anchor bolt, including single anchor, double anchor and butterfly support, which is used to support the keel and panel. The panel is supported by bed support whose area is small, so it belongs to point support.

Bed support is rolled by structural steel galvanized sheet of S280, whose size of the section is shown in Fig. 2. The thickness of single anchor, double anchor and butterfly support is $5.0 \mathrm{~mm}$ or it is determined by the design requirements from different areas. The length of the connecting edge of bed support is $20 \mathrm{~mm}$ more than the thickness of the thermal insulation material at least. It is easy to control the quality of the product because the bed support is precast.

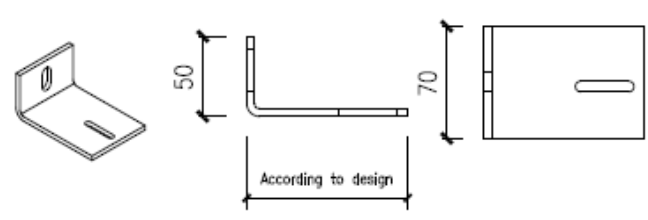

a. Single anchor support

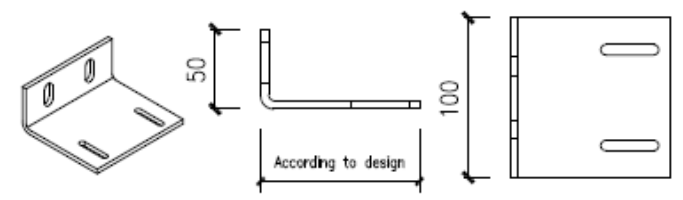

b. Double anchor support
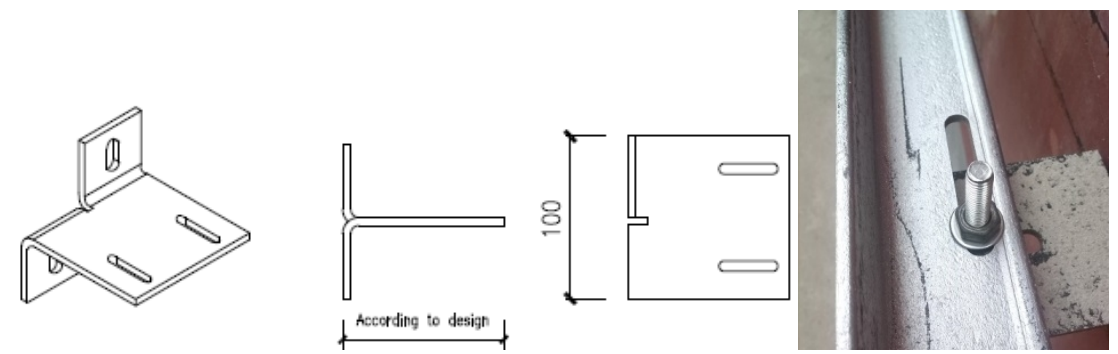

c. Butterfly support

Fig.2. Diagram of bed support (mm)

The location of bed support can be adjusted by slot when drilling needs to avoid steel. Choosing different forms of bed support is conducive to choose a reasonable location of hole. The length of the bed support is depended on the thickness of the insulation material. Support and keel are connected by bolt. To the slot could be adjusted before and after when the wall is not flat.

(2) Keel

The keel of the system is a component installed on external wall with fixed connecting pieces to support the system. The keel is rolled by structural steel galvanized sheet of S280. It is light weight, 
high strength, anti-corrosion, durable and the section is in reasonable design. The section size of keel is shown in Fig. 3 and the thickness is $5.0 \mathrm{~mm}$ or it is determined by the design requirements from different areas.

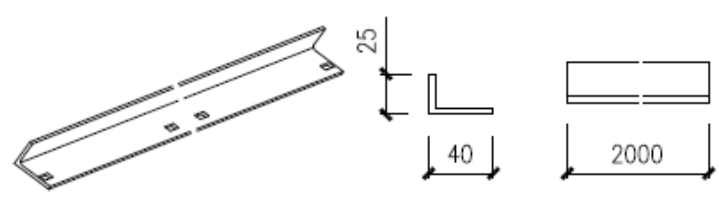

Fig.3. Diagram of keel (mm)

The result of foam block test result proved that the horizontal keel could meet the load requirements, simplify the installation and save materials, so horizontal keel was adopted.

The horizontal keel and bed support are connected by bolts, the slot on keel can be adjusted from left to right or according to the relationship between bed support and keel. Bolts shall fulfil the requirements of GB/T 3098.1 and GB/T 3098.2.

(3) Panel clamp unit

Panel cards comprise interdigitated panel card and panel hook, which are used to fix panel. These cards are made from galvanized steel and precast in factories. The panel card is inserted into the long slot on the side of the panel by tapping screw so as to fix panel on keel. The section size of interdigitated panel is shown in Fig. 4a and the thickness of the panel card is $1.2 \mathrm{~mm}$ or determined by the design requirements from different areas.

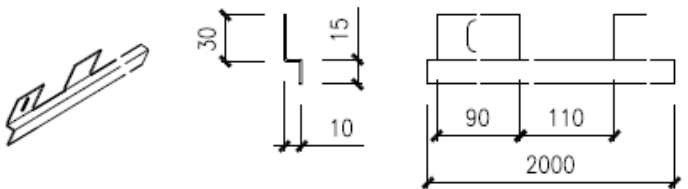

a The size of interdigitated card

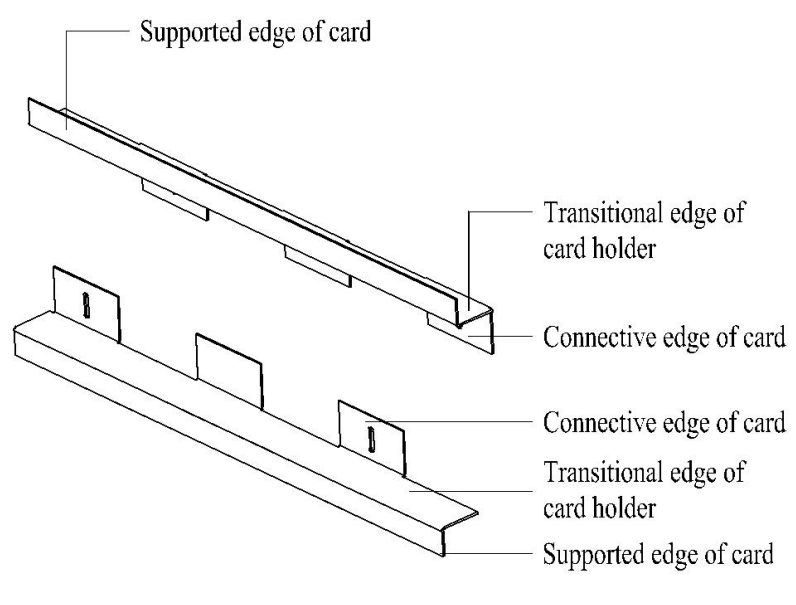

$\mathrm{b}$ The structure of interdigitated card

Fig.4. Interdigitated card (mm)

Fig. $4 \mathrm{~b}$ shows a pair of interdigital cards which are matched to use in the seam position. Two cards up and down interspersed with each other without mutual interference and fixed independently. It can achieve the adjustment from zero to infinite. At the same time, the card piece can be fixed on the keel and adjust the angle. The independent fixed method can remove and install single panel independently when the panel needs replacement and maintenance.

Panel is fixed by interdigitated card with the slot which is on the panel. It is shown in Fig. 5. This fixed way is invisible on the surface of panel, which can beautify the panel. 


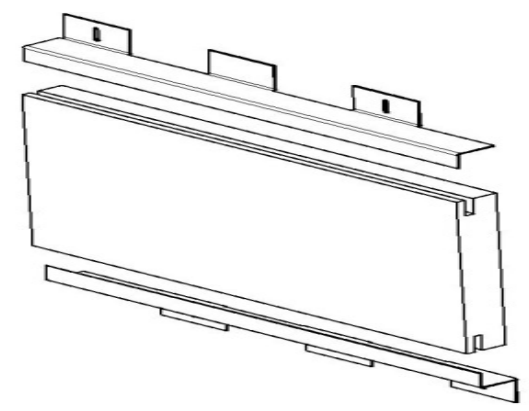

Fig.5 Installed relationship between interdigitated card and panel

(4) Height adjustment heat insulation pad and angle adjusting pad

Thermal insulation system has a high requirement on installed location because of the introduction of decorative panel with certain size and keel structure, so the correcting wedge and insulation adjustment block between bed support and keel should be added. Correcting wedge can adjust angle of keel and insulation adjustment block can adjust the height. The slot between bed support and keel can adjust the three-direction of keel. At the same time, the correcting wedge and insulation adjusting cushion block are made from nylon 66 so as to play the role of "bridge" and "insulation".

The insulation pads are used in pairs and the size of the specification is shown in Fig. 6.

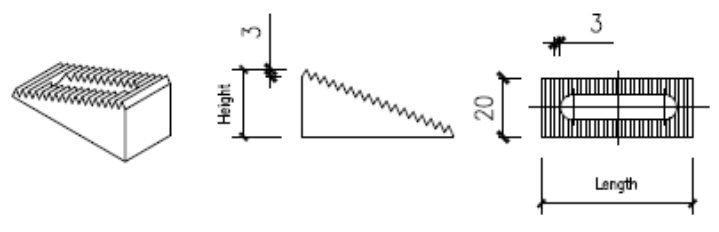

Fig.6. Diagram of insulation pad (mm)

The size of the parts whose height and angle are adjustable is shown in Fig. 7 . The height angle regulator adopts galvanized steel material, which is easy to adjust the fine height, and adjust the angle according to the different insertion position.

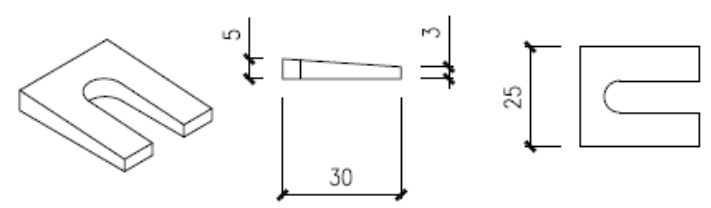

Fig.7. Adjustment of hight and angle

(5) Panel

The compartments of the existing buildings have been investigated and we adopt the basic way of $600 \mathrm{~mm} * 800 \mathrm{~mm}$. It is shown in Fig. 8.

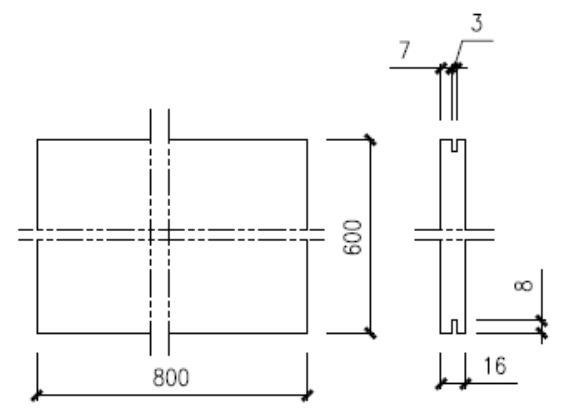

Fig.8. Structural diagram of calcium silicate board 
The way of connection between panel and the support (panel card) is an important factor in design. The fixed way visibly such as anchorage way, the way of panel arranged in the card, not only affects the appearance of panel, but also leads to reduce the durability of metal parts exposed to outdoor environment and oxidized. Finally, we adopt the invisible design inserting the panel card into groove. But this way could reduce the performance of the panel and leads the groove to be the weak spot of the failure of the panel.

(6) Anchor to bed support

The system is fixed by mechanical anchor bolt, and the single anchor bolt's limit value of tensile strength is more than $5.75 \mathrm{KN}$. Anchor bolt is made from carbon steel or alloy steel, and the surface is galvanized. The quality of materials should conform to GB/T 22795 (Expansion anchors for use in concrete-type dimension), GB/T 3098.1 (Mechanical properties of fasteners-Bolts, screws and studs) and GB/T 3098.2 (Mechanical properties of fasteners-Nuts-Coarse thread).

(7) Thermal insulation material

Thermal insulation material needs a certain tensile strength because both insulation materials and thermal insulation structure are under the effect of wind in the thin plastering ETIS. For example, the tensile strength perpendicular to EPS board shall not be less than $0.10 \mathrm{MPa}$ according to the standard of JGJ 144 (technical specification for external thermal insulation on walls). In this system, tensile strength of thermal insulation material is reduced because panel is subjected to wind pressure independently, which can allow more materials which have excellent heat preservation performance but insufficient tensile strength to be used. The inorganic thermal insulation materials suitable for this system are rock wool, glass wool, cellular glass, foam cement, whose flame rating shall be as A. And the organic are molded polystyrene foam, extruded polystyrene foam, polyurethane foam, phenolic foam, whose flame rating shall be as B.

(8) Sealant

The sealant of fabricated ETIS is weathering neutral silicone sealant, which is mainly used in the seam between two panels to seal and proof water. Its technical performance should be consistent with the relevant provisions of GB/T14683 (Silicone sealant for building).

\section{The Basic Properties of the System}

According to the standard of 《Test method of air permeability, water-tightness, wind loud resistance performance , for curtain walls》, test results of the system performance are as follows:

Air permeability performance: Under the pressure of $10 \mathrm{~Pa}$, the air infiltration quantity of unit area is $0.07 \mathrm{~m}^{3} /\left(\mathrm{m}^{2} \cdot \mathrm{h}\right)$ while under $-10 \mathrm{~Pa}$, is $0.09 \mathrm{~m}^{3} /\left(\mathrm{m}^{2} \cdot \mathrm{h}\right)$. The air permeability performance is grade 4 .

Water-tightness performance: The maximum pressure fixed part is $20 \mathrm{kPa}$ when there is no serious leakage happens, and the water-tightness performance is grade 5.

Performance of wind resistance: Safety detection: positive pressure is $5 \mathrm{kPa}$ and negative is $-5.0 \mathrm{kPa}$. Wind resistance performance is grade 9. The maximum anti-wind pressure is negative pressure difference -6300pa.

Plane deformation performance: The displacement angle of inter layer is $1 / 100$, and it is not damaged under the three repeated cycle. The plane deformation performance is grade 5 , indicating that the system has a good performance of resisting earthquake.

There is no foaming or spalling on finish coat, no hollow or exfoliation on protecter, no cracks or seepage after weathering resistance test. The weathering resistance can meet the requirement of JGJ144-2004.

\section{Conclusion}

This paper designed a fabricated ETIS with point supported horizontal keel, which is composed of bed support, horizontal keel, panel, the connector and the thermal insulation material. The ETIS has the ability to adjust the three-dimension and angle and the installation of the panel is invisible, What is more, 
it can be disassembled independently. The performance of wind resistance is grade 9, the plane deformation performance is grade 5, the air impermeability performance is grade 4 , and the water tightness performance is grade 5. Weather resistance could meet the requirements of the relevant standards.

\section{References}

[1] China Railway Airport Construction Group Co., Ltd. CN. Patent 201420824538. (2015). “In Chinese"

[2] Beijing Door and Window developing co., Ltd. CN. Patent 201210515052.3. (2013). "In Chinese"

[3] CHOI J M; et al. KR. Patent 1035973-B1. (2011).

[4] Duttlinger W. DE. Patent 102010014478-A1. (2011).

[5] Shin D; et al. WO. Patent 2015122558-A1. (2015).

[6] Dong I S. KR. Patent 1141158-B1. (2012).

[7] Zhuoda new materials and technology group co., Ltd. CN. Patent 20746968.9. (2016). "In Chinese"

[8] Yajun Wang. CN. Patent 20184852.7. (2012). "In Chinese"

[9] China State Construction Engineering Corporation. CN. Patent 10300293.4. (2009). "In Chinese"

[10] Biebricher B. Thermal insulation composite system[P]. EP. Patent 2562325. (2013).

[11] Sugawara M; Miyamoto N. JP. Patent 2010255357-A. (2010).

[12] Young S J. KR. Patent 2015030345-A. (2015).

[13] Yeol S D. KR. Patent 2013086998-A. (2013).

[14] Yeon Y J, U Cho D, U Chae C, U Jeong J. KR. Patent 1429057-B1. (2014).

[15]ETAG 004 : Guideline for European Technical Approval of External Thermal Insulation Composite Systems with Rendering, (2003). 